VII JORNADAS DE DIFUSIÓN DE LA INVESTIGACIÓN Y EXTENSIÓN - FCV-UNL

RESUMEN EXTENDIDO

\title{
PROPUESTA DE UNA METODOLOGÍA PARA CUANTIFICAR LA ACTIVIDAD ANTIBACTERIANA DE LA MIEL
}

\author{
Ferrer $A^{1}$, Menseguéz $S^{1}$, Anadón $A^{1}$, Dell'Elce $A^{1}$, Castromán $R^{1}$, Candioti $V^{2}$, \\ Picco $E^{1}$, Formentini $E^{1}$.
}

${ }^{1}$ Laboratorio de Farmacología y Toxicología, FCV-UNL

${ }^{2}$ Cátedra de Semiología, FCV-UNL

* Correspondencia: Ferrer A. E-mail: anapaulaferrer.af@gmail.com

Editado por: R. Sobrero, V. Matiller, C. Baravalle

PROPOSAL OF A METHODOLOGY TO QUANTIFY THE ANTIBACTERIAL ACTIVITY OF HONEY.

SUMMARY

In this study a standardized method for objectively comparing the antibacterial activity of honey was developed. The assay was performed using a strain of $S$. aureus and four honeys that have been shown antibacterial activity against this strain. The antibacterial activity of honeys were checked by using an agar plate diffusion method using S. aureus (ATCC 29213) as the test organism. On the surface of each agar plate six stainless steel cylinders with a diameter of $8,14 \mathrm{~mm}$ were radially disposed. Onto each cylinder $0,1 \mathrm{~mL}$ of sample honey at $10 \% \mathrm{v} / \mathrm{v}$ was placed and all Petri dishes were incubated at $35^{\circ} \mathrm{C}$ during $24 \mathrm{~h}$. Each sample were analyzed by trip licate. The surface of the cylinder diameter was set as reference antibacterial activity equivalent to minimal inhibitory concentration (MIC). The antibacterial activity of each honey was quantitated by the relationship between the surface of the inhibitory zone and the surface of the reference activity expressed as multiples of MIC ( $x$ MIC). The method allowed establishing differences between the bacterial activities of the different honeys tested and could be used for identifying honeys that could be employed with medicinal purpose for the treatments of wounds.

Palabras clave: Miel, Staphylococcus aureus, Cuantificación, Actividad antibacteriana.

Keywords: Honey, Staphylococcus aureus, Quantitation, Antibacterial activity.

La actividad antibacteriana de la miel era reconocida en la antigüedad por pueblos como el egipcio o el babilónico, que habían previamente descripto los beneficios de la misma en la prevención de infecciones y la curación de heridas (Malone y Tsai, 2016; Oryan et al., 2016). La actividad antibacteriana de la miel se atribuye a su elevada osmolaridad, acidez, concentración de peróxido de hidrógeno y radicales no peróxidos tales como óxido nítrico y fenoles (Becerra Torrejón et al., 2016). Muchas técnicas in vitro se han reportado para evaluar la actividad antibacteriana de la miel, sin embargo no se ha reportado ningún método estandarizado para realizar comparaciones entre distintas mieles respecto de una actividad basal o de referencia. El objetivo de este trabajo fue desarrollar un método que permitiera comparar de manera objetiva la actividad antibacteriana de distintas mieles. Se utilizó una cepa estandarizada de Staphylococcus aureus y cuatro mieles que en ensayos realizados previamente en el Laboratorio de Farmacología y Toxicología, FCVUNL, habían mostrado actividad antibacteriana in vitro sobre S. aureus (Tabla 1 ).

Con un cultivo nuevo de S. aureus (ATCC 29213) se preparó una suspensión $(0,5 \times 105 \mathrm{ufc} / \mathrm{mL})$ en solución fisiológica con el que se inoculó agar Mueller Hinton esterilizado a una temperatura de $45^{\circ} \mathrm{C}$ a razón de 0,1 $\mathrm{mL}$ de suspensión cada $100 \mathrm{~mL}$ de agar. Se sembraron 
placas con agar hasta un espesor aproximado de $3 \mathrm{~mm}$. Sobre la superficie de cada placa se colocaron en disposición radial cuatro cilindros de acero inoxidable de $8,14 \mathrm{~mm}$ de diámetro y $8,14 \mathrm{~mm}$ de altura. Un volumen de $0,1 \mathrm{~mL}$ de cada miel al $50 \% \mathrm{v} / \mathrm{v}$ se colocó en el interior de cada cilindro. El ensayo fue realizado por triplicado. Las placas se colocaron en estufa a $35^{\circ} \mathrm{C}$ durante $24 \mathrm{~h}$. Transcurrido ese período se retiraron los cilindros y se midió el diámetro del halo de inhibición (A) y el halo central (B) determinado por los bordes del cilindro de acero inoxidable. Asumiendo que el diámetro del halo $\mathrm{A}$ es originado por la migración de los factores con actividad antibacteriana a través de la fase acuosa del agar, se asume que el límite entre la zona de inhibición y la zona de crecimiento (C) corresponde a la concentración inhibitoria mínima de la miel (CIMM). Como actividad de referencia se consideró la superficie del halo de inhibición equivalente el diámetro central del cilindro de acero inoxidable, asumiendo que esa es la menor actividad antibacteriana cuantificable, tal como se presenta en la figura 1.

La cuantificación de la actividad antibacteriana de cada miel se determinó estableciendo la relación entre la superficie del halo central (Sc) y la superficie del halo de inhibición (Si) utilizando las ecuaciones 1 a 3.

$$
\begin{array}{cc}
S_{c}=\pi \cdot\left(r_{c}\right)^{2} \text { donde } r_{c}=\left(\varnothing H_{c}\right) / 2 & \text { Ecuación 1 } \\
S_{i}=\pi \cdot\left(r_{i}\right)^{2} \text { donde } r_{i}=\left(\varnothing H_{i}\right) / 2 & \text { Ecuación 2 } \\
\times C I M=S_{i} / S_{c} & \text { Ecuación 3 }
\end{array}
$$

Donde, Sc y Si son las superficies ( $\mathrm{mm} 2$ ) del halo central y de inhibición respectivamente, rc y ri son los radios del halo central y de inhibición respectivamente, $\varnothing \mathrm{Hc}$ y $\varnothing \mathrm{Hi}$ son los diámetros del halo central y de inhibición. La relación entre Si y Sc determina el valor de los múltiplos de la CIMM presentes en la $\mathrm{Si}$.

Los halos de inhibición resultantes de la actividad de las cuatro mieles se presentan en la figura 2 . La cuantificación de la actividad de las cuatro mieles (A, B, C y D) expresadas como múltiplos del valor de Sc equivalente a la CIMM se presenta en la tabla 2.

Los resultados obtenidos muestran que el procedimiento empleado permitió cuantificar y comparar objetivamente la actividad antibacteriana de las mieles seleccionadas. Si bien todas las mieles deberían presentar actividad antibacteriana, el grado de esta puede variar según las especies florales, la zona geográfica, la estación climática, el procesamiento (cosecha) y la conservación de las mismas. El procedimiento de cuantificación de la actividad antibacteriana presentado en este estudio puede ser empleado para identificar mieles que puedan emplearse con fines medicinales para el tratamiento de heridas.
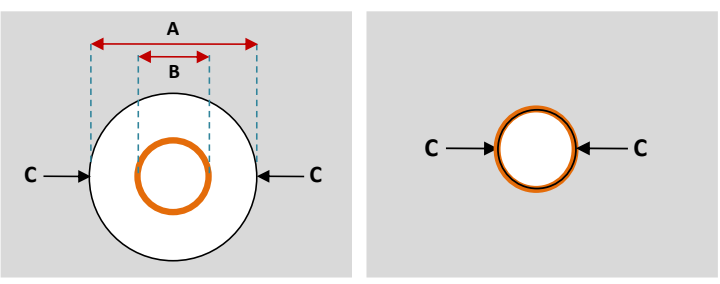

Figura 1. Representación gráfica de la cuantificación de la actividad antibacteriana de miel determinada por la técnica del cilindro en placa. Donde $A$ y $B$ son los diámetros del halo de inhibición y el halo central respectivamente y $C$ corresponde a la interfase equivalente a la concentración inhibitoria mínima de la miel.
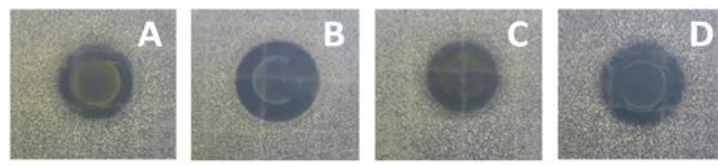

Figura 2. Halos de inhibición resultantes de la actividad sobre S. aureus de cuatro mieles (A, B, C y D) al $50 \%$ v/v sobre placa de agar.

Tabla 1. Caracterización de cuatro tipos de mieles que en ensayos realizados previamente en el Laboratorio de Farmacología y Toxicología, FCV-UNL habían presentado actividad antibacteriana sobre $S$. aureus.

\begin{tabular}{|l|l|l|l|l|}
\hline Identificación & Denominación & $\begin{array}{l}\text { Tipo de } \\
\text { miel }\end{array}$ & $\begin{array}{l}\text { Ciudad de } \\
\text { origen }\end{array}$ & Provincia \\
\hline A & "Monacal" & Comercial & Victoria & Entre Ríos \\
\hline B* & FCV-UNL & Productor & Esperanza & Santa Fe \\
\hline C & "El Ocaso" & Productor & Esquina & Corrientes \\
\hline D & $\begin{array}{l}\text { "Don } \\
\text { Francisco" }\end{array}$ & Productor & $\begin{array}{l}\text { San } \\
\text { Martín }\end{array}$ & Santa Fe \\
\hline
\end{tabular}

(*) Miel producida por el Grupo Funcional Apícola de la FCV en el apiario de la Unidad Académico Productiva (UAP) de la FCVUNL.

Tabla 2. Cuantificación de la actividad de las cuatro mieles (A, B, C y D) expresadas como múltiplos de la superficie de inhibición central (x CIM) equivalente a la CIMM.

\begin{tabular}{c|c|c|c|c|c|c}
\hline Miel & $\% \mathrm{v} / \mathrm{v}$ & \multicolumn{2}{c}{ Halo central } & \multicolumn{2}{c}{ Halo periférico } & Actividad \\
& & $\varnothing$ & $\mathrm{mm}^{2}$ & $\varnothing$ & $\mathrm{mm}^{2}$ & $\mathrm{x} \mathrm{CIM}$ \\
\hline A & & & & 10,5 & 86,0 & 1,65 \\
B & \multirow{2}{*}{50} & \multirow{2}{*}{8,14} & \multirow{2}{*}{52,0} & 11,9 & 110,7 & 2,13 \\
C & & & & 10,4 & 85,7 & 1,65 \\
\hline D & & & & 11,4 & 102,0 & 1,96 \\
\hline
\end{tabular}

\section{Bibliografía}

Becerra Torrejón D, Cabrera Ureña J, Solano M. 2016. Efecto antibacteriano de la miel de abeja en diferentes concentraciones frente a Staphylococcusa aureus. Rev. Cient. Cienc. Med. 19(2): 38- 42.

Malone M, Tsai G. 2016. Wound healing with Apitherapy: A Review of the Effects of Honey. J. Apither. 1(1): 29-32.

Oryan A, Alemzadeh E, Moshiri A. 2016. Biological properties and therapeutic activities of honey in wound 
healing: A narrative review and meta-analysis. J. Tissue Viability. 25(2): 98-118. 